\title{
CDISC SEND Death Diagnosis Test Name Terminology
}

National Cancer Institute

\section{Source}

National Cancer Institute. CDISC SEND Death Diagnosis Test Name Terminology. NCI

Thesaurus. Code C89965.

The terminology that includes concepts relevant to the Clinical Data Interchange Standards Consortium (CDISC) Standard for the Exchange of Non-clinical Data (SEND) death diagnosis test names. 